\title{
A Score of Low-Grade Inflammation for Predicting Stroke Recurrence in Patients with Ischemic Stroke
}

Min Wu, (D) ${ }^{1, *}$ Xiaohao Zhang, (D) ${ }^{2, *}$ Jingjing Chen, ${ }^{3, *}$ Mingming Zha, (D) ${ }^{4}$ Kang Yuan, (D) ${ }^{5}$ Kangmo Huang, (D) ${ }^{2}$ $\mathrm{Yi} \mathrm{Xie}^{2}$ Jianzhong Xue, ${ }^{6}$ Xinfeng Liu (iD) ${ }^{1,2,7}$

'Department of Neurology, Jinling Hospital, The First School of Clinical Medicine, Southern Medical University, Nanjing, 210002, People's Republic of China; ${ }^{2}$ Department of Neurology, Jinling Hospital, Affiliated Medical School of Nanjing University, Nanjing, 210002, People's Republic of China; ${ }^{3}$ Department of Neurology, Changhai Hospital, Navy Medical University, Shanghai, 200433, People's Republic of China; ${ }^{4}$ Department of Neurology, Jinling Hospital, Medical School of Southeast University, Nanjing, 210002, People's Republic of China; ${ }^{5}$ Department of Neurology, Jinling Hospital, Nanjing Medical University, Nanjing, 210000 , People's Republic of China; ${ }^{6}$ Department of Neurology, Changshu No.2 People's Hospital, Changshu, People's Republic of China; ${ }^{7}$ Stroke Center \& Department of Neurology, the First Affiliated Hospital of USTC, Division of Life Sciences and Medicine, University of Science and Technology of China, Hefei, Anhui, 23000I, People's Republic of China

*These authors contributed equally to this work

Correspondence: Xinfeng Liu Department of Neurology, Jinling Hospital, The First School of Clinical Medicine, Southern Medical University, No. 305 Zhongshan East Road, Xuanwu District, Nanjing, Jiangsu Province, 210002 , People's Republic of China Tel +86 I38 I3835 I I4

Email xfliu2@vip.I63.com

Jianzhong Xue

Department of Neurology, Changshu

No.2 People's Hospital, No. 18 Taishan

Road, Changshu, Jiangsu Province,

People's Republic of China

Tel +86 I3506247572

Email xjz2021@sina.com
Background and Purpose: The impact of low-grade inflammation (LGI) on stroke recurrence has not been well studied yet. We aimed to evaluate the association between LGI and stroke recurrence in patients with ischemic stroke.

Methods: Patients with first-ever ischemic stroke diagnosed within 72 hours of symptoms onset were consecutively recruited from the Nanjing Stroke Registry Program. C-reactive protein (CRP) level, white blood cell (WBC) count, platelet (PLT) count, and neutrophil-tolymphocyte ratio (NLR) were conceived as low-grade inflammation biomarkers and combined into a standardized LGI score. The association of LGI score with the risk of stroke recurrence was analyzed with multivariate Cox regression models. Analyses accounting for the competing risk of stroke recurrence and death were also performed.

Results: Of the 1214 patients studied (median age, 61 years; male, 71.6\%), 177 (14.6\%) patients experienced a recurrent stroke with a median follow-up of 23.0 (interquartile ranges, 14.5-34.0) months. Patients with stroke recurrence had a higher LGI score (median, 3 versus $-2 ; P<0.001)$ than those without recurrence. The univariate analysis indicated that patients with LGI scores in the fourth quartile were more likely to have a stroke recurrence (hazard ratios $[\mathrm{HR}], 4.312 ; 95 \%$ confidence interval $[\mathrm{CI}], 2.675-6.952 ; P<0.001)$. After adjusting for potential confounders, the association remained significant in the multivariate Cox regression model (HR, 4.080; 95\% CI, 2.420-6.879; $P<0.001$ ). Competing risks model and sensitivity analysis further confirmed this conclusion.

Conclusion: This study showed that an elevated LGI score was associated with a higher risk of stroke recurrence, independent of other vascular risk factors.

Keywords: low-grade inflammation, stroke recurrence, ischemic stroke, predictor

\section{Introduction}

In most countries, the incidence of ischemic stroke is increasing with the age of the general population. ${ }^{1,2}$ A recurrent stroke occurs more frequently during the first years after stroke, with estimated frequency ranging between $7.1 \%$ and $26.0 \%$, depending on the population studied and the length of follow-up. ${ }^{3-5}$ Furthermore, stroke recurrence is more fatal and disabling than the first-ever stroke. ${ }^{6}$ Thus, early identification and management of the high risk of recurrent stroke patients are of great significance.

Low-grade inflammation (LGI) has been reported to be associated with several chronic conditions including cardiovascular disease, cancer, and neurodegenerative disease. $^{7-9}$ Due to the sensitivity to lifestyle modifications, LGI also emerged as an important target for disease prevention. ${ }^{10}$ Several biomarkers, both circulating (ie, 
C-reactive protein [CRP]) and cellular (ie, platelet [PLT] and white blood cell [WBC] count) have been recognized as indicators of LGI. ${ }^{11,12}$ The CAPRIE study (Clopidogrel versus Aspirin in Patients at Risk of Ischemic Events) demonstrated that increased leukocyte count was related to recurrent ischemic stroke. ${ }^{13}$ However, several large-scale epidemiological studies on CRP level and recurrent vascular events yielded inconsistent results, some showing significant positive associations between CRP and stroke recurrence, ${ }^{14}$ whereas others indicated no association. ${ }^{15}$ Recently, the neutrophil-to-lymphocyte ratio (NLR) was also shown to be a reliable marker of cellular inflammation. ${ }^{16}$ Considering that these LGI markers do not occur separately in a patient, a comprehensive approach that takes into account the possible synergistic effects might better illustrate the LGI status. Meanwhile, the association of LGI status with recurrent stroke has not been fully investigated.

Thus, the study aimed to use a predefined composite LGI score based on the 4 abovementioned individual LGI markers and to investigate its relationship with stroke recurrence in a cohort of patients who initially presented with first-ever ischemic stroke.

\section{Materials and Methods Study Population}

Patients with first-ever ischemic stroke were consecutively enrolled in the Nanjing Stroke Registry Program (NSRP) from January 2012 to December 2016. It is a prospective, ongoing, hospital-based stroke registry inaugurated in July 2002. The detailed protocol for this registry has been published previously. ${ }^{5,17}$ Patients were enrolled if they met the following criteria: (a) age $\geq 18$ years; (b) symptoms from onset to admission $<72$ hours. The excluded criteria were as follows: (a) patients experienced infection within recent 30 days; (b) suffered from previous neurological diseases such as cerebral hemorrhage, severe head trauma, and central nervous system infection; (c) had severe hepatic or renal disease, hematological disease, malignant tumor, autoimmune disease, and immunosuppressive therapy. Investigation on the NSRP was approved by the Ethics Review Board of Jinling Hospital (approval number 2010NLY018). All participants or their relatives signed written consent forms. This study was conducted in accordance with the Declaration of Helsinki.

\section{Data Collection}

Demographic characteristics, clinical variables, vascular risk factors, laboratory results, and stroke etiology were all collected and evaluated. Baseline stroke severity was assessed by the National Institute of Health Stroke Scale (NIHSS) score. ${ }^{18}$ Stroke etiology was classified according to the Trial of ORG 10172 in acute stroke treatment classification. ${ }^{19}$ Subjects were defined as smokers if they smoked $>400$ cigarettes in their lifetime. ${ }^{20}$ They were further classified as former smokers if they had quit smoking for at least 30 days before the index stroke, quitters who had quit for at least 1 month and kept cessation at the first follow-up, and the persistent who continued smoking at the first follow-up. ${ }^{21}$ The educational levels were categorized into four groups according to the educational years: 0-6 years (primary school), 6-9 years (middle school), 9-12 years (high school), and $>12$ (university or higher education).

\section{Measurement of LGI}

Blood samples were obtained from each subject within 24 $\mathrm{h}$ after admission. The CRP level, WBC count, PLT count, and NLR were measured and combined into the LGI score. For calculating the LGI score, 10-tiles of each biomarker level (CRP, WBC, PLT, NLR) were generated. Being in the highest deciles $(>6)$ of all individual LGI markers gave a score that increased from 1 to 4 , while being in the lowest deciles $(<5)$ was negatively scored from -4 to -1 . The middle deciles (5 and 6) were assigned a score of 0. The LGI score was the sum of the 4 markers and ranged between -16 and 16 (Figure 1). ${ }^{11}$

\section{Endpoint and Follow-Up Assessments}

The primary endpoint was the fatal or nonfatal stroke recurrence after 3 months of the index stroke, which is defined as a new neurological deficit or a sudden deterioration of a previous deficit lasting for $>24 \mathrm{~h}$, in the absence of apparent causes other than that of vascular origin. ${ }^{22}$ The follow-up was initiated at the 3, 6, 12 months after the index stroke and annually thereafter and extended to the date of the first recurrent stroke or censoring via telephone interviews or clinical visits. ${ }^{5}$ Patients were censored at the date of the emigration from this study, the date of death from other causes, or the end of the assigned follow-up period. The death was verified by examining the death certificates and medical records. 


\section{Low-grade inflammation score}

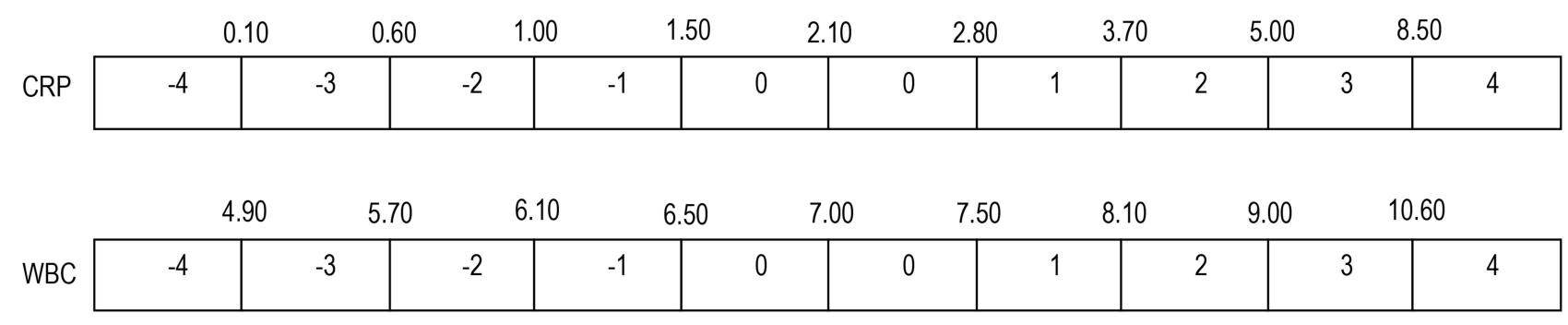

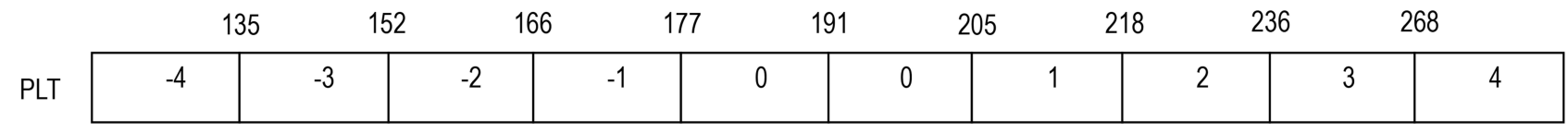

\begin{tabular}{|c|c|c|c|c|c|c|c|c|c|c|}
\hline & & & 1.67 & 1.94 & 2.21 & 2.54 & 2.92 & 3.45 & 4.46 & 6.53 \\
\hline NLR & -4 & -3 & -2 & -1 & 0 & 0 & 1 & 2 & 3 & 4 \\
\hline
\end{tabular}

\begin{tabular}{|llllllllll|}
\hline 10 & -12 & -8 & -4 & 0 & 0 & 4 & 8 & 12 & 16
\end{tabular}

Figure I The calculation of low-grade inflammation score.

Abbreviations: CRP, C-reactive protein; WBC, white blood cell; PLT, platelet; NLR, neutrophil-to-lymphocyte ratio.

\section{Statistical Analysis}

Statistical analysis was performed using SPSS software, version 24.0 (SPSS Inc., Chicago, IL), and R statistical software, version 4.0.0. (R Foundation, Vienna, Austria). Categorical variables were expressed as numbers (percentages) and analyzed with Chi-square or Fisher's exact test. Continuous variables were presented as mean (standard deviations) or median (interquartile ranges, IQR) and analyzed by $t$-test, Mann-Whitney $U$-test, one-way analysis of variance, and Kruskal-Wallis test as appropriate.

The collinearity between candidate variables was examined using variance inflation factors before developing the Cox proportional hazards models, which were performed to estimate hazard ratios (HR) with a $95 \%$ confidence interval (CI) concerning stroke recurrence. Model 1 adjusted for age and sex, and model 2 adjusted for age, sex, and factors with a $P$-value $<0.1$ in the univariate analysis, of which the predictive capacity was measured by concordance index (c-index). The receiver operating characteristics (ROC) curve was performed to examine the discrimination of the LGI score and the individual biomarkers of the score. The cumulative incidence curves of stroke recurrence were also plotted according to the LGI score using Kaplan-Meier survival analysis. Moreover, the higher LGI score is a significant risk factor for death and the Fine and Gray's proportional subdistribution hazards regression models were used to examine the possible influence of death on the association between LGI score and risk of recurrent stroke. ${ }^{23}$

Meanwhile, the LGI score might differ according to sex, age, cardiovascular risk factors, blood pressure at admission, and baseline stroke severity, which are also important factors of stroke recurrence. Thus, sensitivity analysis was performed by stratifying participants into different subgroups, and tests of interaction were also performed in terms of the factors aforementioned.

Moreover, the associations of LGI scores with different stroke subtypes were further analyzed using Fisher's exact test with the Bonferroni methods. A two-tailed $P$-value $<0.05$ was considered statistically significant.

\section{Results}

Of the 1214 participants included in this study, the median age was 61 years and $869(71.6 \%)$ were male. The median levels of CRP, WBC count, PLT count, and NLR were 
$2.1 \mathrm{mg} / \mathrm{L}, 7.0 \times 10^{9} / \mathrm{L}, 191 \times 10^{9} / \mathrm{L}$, and 2.5 , respectively. During an average follow-up of 23.0 (IQR, 14.5-34.0) months, $177(14.6 \%)$ patients experienced a recurrent stroke, of which 159 patients with ischemic stroke and 18 with hemorrhagic stroke.

Table 1 shows the clinical characteristics of the study sample stratified by the quartile of LGI score. Compared with patients in the first quartile of LGI scores, those with increasing LGI scores had a higher ratio of large-artery atherosclerosis $(P=0.003)$, a lower education level $(P<0.001)$, and a higher baseline NIHSS score $(P<0.001)$.

Table 2 illustrates the demographic characteristics, clinical data, and laboratory data according to the presence or absence of stroke recurrence. Patients with recurrence were older (median age, 66 versus 60 years, $P<0.001$ ), had a higher prevalence of large artery atherosclerosis

Table I Baseline Data According to the Quartile of Low-Grade Inflammation Score

\begin{tabular}{|c|c|c|c|c|c|c|}
\hline Variables & $\begin{array}{l}\text { All Patients } \\
n=1214\end{array}$ & $\begin{array}{l}\text { QI (s-5) } \\
n=335\end{array}$ & $\begin{array}{l}\text { Q2 }(-4 \text { to }-1) \\
n=278\end{array}$ & $\begin{array}{l}Q 3(0 \text { to } 4) \\
n=331\end{array}$ & $\begin{array}{l}\text { Q4 (>4) } \\
n=270\end{array}$ & $P$ for Trend \\
\hline Age, years, median [IQR] & $61(52,68)$ & $62(54,68)$ & $61(52,67)$ & $61(51,69)$ & $59(49,67)$ & 0.052 \\
\hline Male, n (\%) & $869(71.6)$ & $234(69.9)$ & $205(73.7)$ & $233(70.4)$ & $197(73.0)$ & 0.656 \\
\hline BMI, $\mathrm{kg} / \mathrm{m}^{2}$, median $[\mathrm{IQR}]$ & $24.5(22.5,26.6)$ & $24.4(22.5,26.3)$ & $24.7(22.7,26.8)$ & $24.5(22.9,27.0)$ & $24.7(22.9,26.3)$ & 0.366 \\
\hline Baseline NIHSS score, median [IQR] & $4.0(2.0,8.0)$ & $3.0(1.0,6.0)$ & $3.0(1.0,6.0)$ & $4.0(2.0,8.0)$ & $5.0(2.0,10.0)$ & $<0.001$ \\
\hline $\begin{array}{l}\text { Stroke subtypes, n (\%) } \\
\text { LAA } \\
\text { CE } \\
\text { SAA } \\
\text { Others }\end{array}$ & $\begin{array}{l}469(38.6) \\
113(9.3) \\
248(20.4) \\
384(31.6)\end{array}$ & $\begin{array}{l}117(34.9) \\
30(9.0) \\
87(26.0) \\
101(30.1)\end{array}$ & $\begin{array}{l}99(35.6) \\
23(8.3) \\
70(25.2) \\
86(30.9)\end{array}$ & $\begin{array}{l}134(40.5) \\
30(9.1) \\
59(17.8) \\
108(32.6)\end{array}$ & $\begin{array}{l}119(44.1) \\
30(11.1) \\
32(11.9) \\
89(33.0)\end{array}$ & 0.003 \\
\hline $\begin{array}{l}\text { Education years, } n(\%) \\
\qquad 0-6 \\
6-9 \\
9-12 \\
>12\end{array}$ & $\begin{array}{l}314(25.9) \\
619(51.0) \\
143(11.8) \\
138(11.4)\end{array}$ & $\begin{array}{l}98(29.3) \\
152(45.4) \\
43(12.8) \\
42(12.5)\end{array}$ & $\begin{array}{l}74(26.6) \\
127(45.7) \\
42(15.1) \\
35(12.6)\end{array}$ & $\begin{array}{l}93(28.1) \\
172(52.0) \\
43(13.0) \\
23(6.9)\end{array}$ & $\begin{array}{l}49(18.1) \\
168(62.2) \\
15(5.6) \\
38(14.1)\end{array}$ & $<0.001$ \\
\hline $\begin{array}{l}\text { Vascular risk factors, n (\%) } \\
\text { Hypertension } \\
\text { Diabetes mellitus } \\
\text { Hyperlipidemia } \\
\text { Coronary heart disease }\end{array}$ & $\begin{array}{l}848(69.9) \\
355(29.2) \\
123(10.1) \\
86(7.1)\end{array}$ & $\begin{array}{l}244(72.8) \\
99(29.6) \\
30(9.0) \\
29(8.7)\end{array}$ & $\begin{array}{l}186(66.9) \\
78(28.1) \\
31(11.2) \\
17(6.1)\end{array}$ & $\begin{array}{l}234(70.7) \\
98(29.6) \\
37(11.2) \\
25(7.6)\end{array}$ & $\begin{array}{l}184(68.1) \\
80(29.6) \\
25(9.3) \\
15(5.6)\end{array}$ & $\begin{array}{l}0.385 \\
0.970 \\
0.694 \\
0.436\end{array}$ \\
\hline $\begin{array}{l}\text { Smoking status, n (\%) } \\
\text { Nonsmokers } \\
\text { Former smokers } \\
\text { Quitters } \\
\text { Persistent smokers }\end{array}$ & $\begin{array}{l}520(42.8) \\
115(9.5) \\
325(26.8) \\
254(20.9)\end{array}$ & $\begin{array}{l}157(46.9) \\
36(10.7) \\
84(25.1) \\
58(17.3)\end{array}$ & $\begin{array}{l}112(40.3) \\
21(7.6) \\
81(29.1) \\
64(23.0)\end{array}$ & $\begin{array}{l}135(40.8) \\
37(11.2) \\
83(25.1) \\
76(23.0)\end{array}$ & $\begin{array}{l}116(43.0) \\
21(7.8) \\
77(28.5) \\
56(20.7)\end{array}$ & 0.316 \\
\hline Baseline SBP, mmHg, median [IQR] & $140(130,152)$ & $137(128,150)$ & $142(130,153)$ & $140(130,154)$ & $140(130,152)$ & 0.002 \\
\hline Baseline DBP, mmHg, median [IQR] & $80(75,90)$ & $80(74,85)$ & $80(75,90)$ & $80(76,90)$ & $80(75,90)$ & 0.002 \\
\hline Blood glucose, mmol/L, median [IQR] & $5.8(4.9,7.5)$ & $5.4(4.6,6.7)$ & $5.6(4.8,7.2)$ & $6.1(5.0,8.0)$ & $6.3(5.3,7.9)$ & $<0.001$ \\
\hline CRP, mg/L, median [IQR] & $2.1(0.7,4.2)$ & $0.8(0.1,2.1)$ & $1.5(0.3,2.9)$ & $2.7(1.2,4.4)$ & $4.9(2.8,8.9)$ & $<0.001$ \\
\hline WBC count, $10^{9} / \mathrm{L}$, median [IQR] & $7.0(5.9,8.5)$ & $5.6(4.7,6.3)$ & $6.6(5.9,7.5)$ & $7.6(6.6,8.7)$ & $9.5(8.1,11.2)$ & $<0.001$ \\
\hline PLT count, $10^{9} / \mathrm{L}$, median $[\mathrm{IQR}]$ & $191(159,227)$ & $163(139,188)$ & $191(165,219)$ & $196(165,232)$ & $228(196,266)$ & $<0.001$ \\
\hline NLR, median [IQR] & $2.5(1.8,3.9)$ & $1.8(1.4,2.4)$ & $2.2(1.7,2.8)$ & $2.9(2.1,4.0)$ & $5.0(3.2,8.2)$ & $<0.001$ \\
\hline Stroke recurrence, n (\%) & $177(14.6)$ & $22(6.6)$ & $26(9.4)$ & $57(17.2)$ & $72(26.7)$ & $<0.001$ \\
\hline
\end{tabular}

Abbreviations: IQR, interquartile ranges; BMI, body mass index; NIHSS, National Institute of Health Stroke Scale; LAA, large-artery atherosclerosis; CE, cardioembolism; SAA, small-vessel occlusion; SBP, systolic blood pressure; DBP, diastolic blood pressure; CRP, C-reactive protein; WBC, white blood cell; PLT, platelet; NLR, neutrophil-tolymphocyte ratio. 
Table 2 Comparison of Baseline Data According to Patients with and without Recurrence

\begin{tabular}{|c|c|c|c|c|c|}
\hline Variables & $\begin{array}{l}\text { Recurrence } \\
n=177\end{array}$ & $\begin{array}{l}\text { Without Recurrence } \\
n=1037\end{array}$ & $\boldsymbol{P}$ & $\begin{array}{l}\text { Unadjusted HR } \\
(95 \% \mathrm{Cl})\end{array}$ & $P$ \\
\hline Age, years, median [IQR] & $66(57,73)$ & $60(51,67)$ & $<0.001$ & $1.035(1.021-1.049)$ & $<0.001$ \\
\hline Male, n (\%) & $132(74.6)$ & 737 (7I.I) & 0.339 & $1.153(0.822-1.618)$ & 0.408 \\
\hline BMI, kg/m2, median [IQR] & $24.5(23.1,26.7)$ & $24.6(22.5,26.6)$ & 0.499 & $1.006(0.960-1.055)$ & 0.793 \\
\hline Baseline NIHSS score, median [IQR] & $4.0(2.0,8.0)$ & $4.0(2.0,7.0)$ & 0.179 & $1.017(0.993-1.04 I)$ & 0.164 \\
\hline $\begin{array}{l}\text { Stroke subtypes, } n(\%) \\
\text { LAA } \\
\text { CE } \\
\text { SAA } \\
\text { Others }\end{array}$ & $\begin{array}{l}78(44.1) \\
18(10.2) \\
24(13.6) \\
57(32.2)\end{array}$ & $\begin{array}{l}391(37.7) \\
95(9.2) \\
224(21.6) \\
327(31.5)\end{array}$ & 0.087 & $\begin{array}{l}\text { Reference } \\
1.027(0.615-1.715) \\
0.537(0.340-0.848) \\
0.898(0.638-1.264)\end{array}$ & $\begin{array}{l}0.056 \\
0.918 \\
0.008 \\
0.538\end{array}$ \\
\hline $\begin{array}{l}\text { Education years, } \mathrm{n}(\%) \\
\begin{array}{l}0-6 \\
6-9 \\
9-12 \\
>12\end{array}\end{array}$ & $\begin{array}{l}57(32.2) \\
85(48.0) \\
22(12.4) \\
13(7.3)\end{array}$ & $\begin{array}{l}257(24.8) \\
534(51.5) \\
121(11.7) \\
125(12.1)\end{array}$ & 0.086 & $\begin{array}{l}\text { Reference } \\
0.691(0.494-0.967) \\
0.693(0.423-1.136) \\
0.434(0.237-0.794)\end{array}$ & $\begin{array}{l}0.026 \\
0.031 \\
0.146 \\
0.007\end{array}$ \\
\hline $\begin{array}{l}\text { Vascular risk factors, n (\%) } \\
\text { Hypertension } \\
\text { Diabetes mellitus } \\
\text { Hyperlipidemia } \\
\text { Coronary heart disease }\end{array}$ & $\begin{array}{l}132(74.6) \\
60(33.9) \\
16(9.0) \\
11(6.2)\end{array}$ & $\begin{array}{l}716(69.0) \\
295(28.4) \\
107(10.3) \\
75(7.2)\end{array}$ & $\begin{array}{l}0.138 \\
0.141 \\
0.602 \\
0.626\end{array}$ & $\begin{array}{l}I .28 I(0.9 \mid 3-1.797) \\
I .254(0.9|8-| .7 \mid 2) \\
0.848(0.507-1.4 I 7) \\
0.933(0.507-1.7 \mid 8)\end{array}$ & $\begin{array}{l}0.152 \\
0.154 \\
0.528 \\
0.823\end{array}$ \\
\hline $\begin{array}{l}\text { Smoking status, n (\%) } \\
\text { Nonsmokers } \\
\text { Former smokers } \\
\text { Quitters } \\
\text { Persistent smokers }\end{array}$ & $\begin{array}{l}56(31.6) \\
24(13.6) \\
30(16.9) \\
67(37.9)\end{array}$ & $\begin{array}{l}464(44.7) \\
91(8.8) \\
295(28.4) \\
187(18.0)\end{array}$ & $<0.001$ & $\begin{array}{l}\text { Reference } \\
2.086(1.293-3.366) \\
0.851(0.546-1.326) \\
2.481(1.740-3.539)\end{array}$ & $\begin{array}{l}<0.001 \\
0.003 \\
0.476 \\
<0.001\end{array}$ \\
\hline $\begin{array}{l}\text { Baseline SBP, n (\%) } \\
\quad \geq 140 \mathrm{mmHg}\end{array}$ & $105(59.3)$ & $566(54.6)$ & $0.24 I$ & $1.237(0.916-1.670)$ & 0.164 \\
\hline $\begin{array}{l}\text { Baseline DBP, n (\%) } \\
\quad \geq 90 \mathrm{mmHg}\end{array}$ & $50(28.2)$ & $289(27.9)$ & 0.917 & $0.984(0.709-1.364)$ & 0.921 \\
\hline Glucose, mmol/L, median [IQR] & $6.3(5.1,8.0)$ & $5.8(4.9,7.5)$ & 0.050 & I.024 (0.980-I.07I) & 0.287 \\
\hline CRP, mg/L, median [IQR] & $4.2(1.5,7.9)$ & $2.0(0.7,3.9)$ & $<0.001$ & $1.019(1.008-1.029)$ & $<0.001$ \\
\hline WBC count, $10^{9} / \mathrm{L}$, median [IQR] & $7.7(6.7,9.4)$ & $6.9(5.8,8.3)$ & $<0.001$ & $1.162(1.109-1.216)$ & $<0.001$ \\
\hline PLT count, $10^{9} / \mathrm{L}$, median [IQR] & $199(160,239)$ & $190(158,226)$ & 0.076 & $1.003(1.000-1.005)$ & 0.024 \\
\hline NLR, median [IQR] & $3.2(2.1,6.2)$ & $2.4(1.8,3.6)$ & $<0.001$ & I.092 (I.070-I.II4) & $<0.001$ \\
\hline LGI score, median [IQR] & $3(-1,8)$ & $-2(-5,3)$ & $<0.001$ & I.I03 (I.077-I.I30) & $<0.001$ \\
\hline
\end{tabular}

Abbreviations: HR, hazard ratio; $\mathrm{Cl}$, confidence interval; IQR, interquartile ranges; BMI, body mass index; NIHSS, National Institute of Health Stroke Scale; LAA, largeartery atherosclerosis; CE, cardioembolism; SAA, small-vessel occlusion; SBP, systolic blood pressure; DBP, diastolic blood pressure; CRP, C-reactive protein; WBC, white blood cell; PLT, platelet; NLR, neutrophil-to-lymphocyte ratio; LGI, low-grade inflammation.

numerically ( $44.1 \%$ versus $37.7 \%, P=0.087)$, and were more likely to be persistent smokers $(37.9 \%$ versus $18.0 \%, P<0.001$ ). The levels of CRP level (median, 4.2 versus $2.0 \mathrm{mg} / \mathrm{L}, P<0.001$ ), WBC count (median, 7.7 versus $6.9 \times 10^{9} / \mathrm{L}, P<0.001$ ), and NLR (median, 3.2 versus $2.4, P<0.001)$ were higher in those with recurrence. There was only a numerical difference in the level of PLT count (median, 199 versus $190 \times 10^{9} / \mathrm{L}, P=0.076$ ). 
In univariate analysis, the older age (HR, 1.035; 95\% CI, 1.021-1.049; $P<0.001$ ), stroke types (small-vessel occlusion versus large-artery atherosclerosis; HR, 0.537; 95\% CI, $0.340-0.848 ; P=0.008)$, shorter education years $(>12$ versus 0-6; HR, 0.434; 95\% CI, 0.237-0.794; $P=0.007)$, smoking status (persistent smokers versus nonsmokers; HR, 2.481; 95\% CI, 1.740-3.539; $P<0.001$ ), high level of CRP (HR, 1.019; 95\% CI, 1.008-1.029; $P<0.001$ ), WBC (HR, 1.162; 95\% CI, 1.109-1.216; $P<0.001)$, PLT (HR, 1.003; 95\% CI, $1.000-1.005 ; P=0.024$ ), and NLR (HR, 1.092; 95\% CI, $1.070-1.114 ; P<0.001)$ were associated with increased risk of recurrent stroke. The LGI status, measured by a composite score, was also an independent predictor of recurrent stroke (HR, 1.103; 95\% CI, 1.077-1.130; $P<0.001$ ). The association of LGI status with recurrent stroke using Kaplan-Meier analysis is shown in Figure 2.

Table 3 exhibits the associations of LGI score with stroke recurrence. In the multivariate Cox regression analysis, after adjusting for age and sex, patients with LGI score in the fourth quartile, compared with the first quartile, were associated with a higher risk of stroke recurrence (HR, 4.833; 95\% CI, 2.994-7.799, $P<0.001$; Model 1). In model 2, after adjusting for age, sex, and confounders with a $P$-value $<0.1$ in univariate analysis, LGI score in the fourth quartile was independently associated with recurrent stroke (HR, 4.080; 95\% CI, 2.420-6.879; $P<0.001$ ),

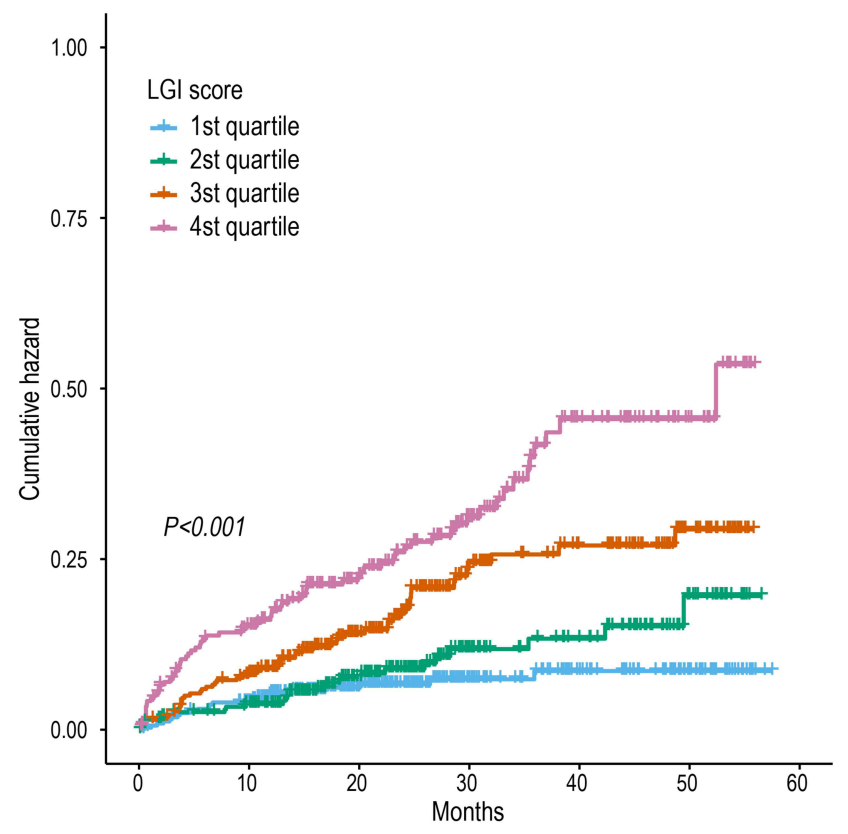

Figure 2 Cumulative incidence rates of stroke recurrence according to the quartile of low-grade inflammation score.

Abbreviation: LGI, low-grade inflammation. and the c-index of the final model was 0.722 . The area under the ROC curve of the LGI score was highest compared with the single biomarker (Figure 3).

After adjusting for the potential confounders in the aforementioned model 2, multivariate competing-risk regression analysis confirmed that the LGI score was also an independent predictor of higher risk of recurrent stroke (The fourth quartile versus the first quartile; HR, 3.555; 95\% CI, 1.802-7.012; $P<0.001)$.

\section{Subgroup Analysis}

In a further sensitivity analysis, after controlling the possible confounders with stratified analysis, the LGI score in the fourth quartile was independently associated with the risk of stroke recurrence (Table 4). Furthermore, a higher risk of increasing LGI score was found in the participants with a lower level of education $(P$ for interaction $<0.001$, Table 4), which suggested a significant interaction between LGI status and education levels.

Supplemental Table 1 shows the comparisons of LGI status in different stroke subtypes. Compared with patients without recurrence, the proportion of the fourth quartile of LGI score was significantly higher in recurrent ischemic stroke or intracranial hemorrhage patients $(19.1 \%$ versus $39.0,19.1 \%$ versus $55.6 \%$, both $P<0.05$ ), while there was no significant difference between the ischemic stroke and intracranial hemorrhage groups $(39.0 \%$ versus $55.6 \%$, $P>0.05)$.

\section{Discussion}

In the present study, we performed a score of LGI based on plasmatic (CRP) and cellular (WBC count, PLT count, and NLR) biomarkers in patients with first-ever ischemic stroke, and found that it was an independent predictor of stroke recurrence.

Recurrent stroke is more devastating with prolonged hospitalization and higher morbidity compared with the first-ever stroke. ${ }^{24}$ LGI status was the common soil involving pathogenetic mechanism among several age-related chronic diseases, ${ }^{7-9}$ but the association between increased LGI condition and stroke recurrence is not well established. Several studies have reported that the CRP, WBC count, PLT count, and NLR are reliable indicators of inflammation status. ${ }^{11,12,16}$ The processes of inflammation and recurrent stroke are complex. Numerous studies have explored the association between LGI condition and stroke recurrence only using a single biomarker approach, rather than considering a panel of combined selected 
Table 3 Associations of Low-Grade Inflammation Score with Stroke Recurrence

\begin{tabular}{|c|c|c|c|c|}
\hline \multirow[t]{2}{*}{ Variables } & \multicolumn{2}{|c|}{ Cox Regression Model } & \multicolumn{2}{|c|}{ Competing Risk Analysis } \\
\hline & HR $(95 \% \mathrm{Cl})$ & $P$ & HR (95\% Cl) & $P$ \\
\hline \multicolumn{5}{|l|}{ Crude model } \\
\hline \multicolumn{5}{|l|}{ Quartile of LGI score } \\
\hline Ist quartile & $1.00($ ref) & & $1.00($ ref $)$ & \\
\hline 2nd quartile & $1.443(0.818-2.546)$ & 0.205 & $\mathrm{I} .430(0.8 \mathrm{II}-2.530)$ & 0.220 \\
\hline 3rd quartile & $2.687(1.643-4.395)$ & $<0.001$ & $2.690(1.640-4.400)$ & $<0.001$ \\
\hline 4th quartile & $4.312(2.675-6.952)$ & $<0.001$ & $4.190(2.597-6.770)$ & $<0.001$ \\
\hline \multicolumn{5}{|l|}{ Model I } \\
\hline \multicolumn{5}{|l|}{ Quartile of LGI score } \\
\hline Ist quartile & 1.00 (ref) & & 1.00 (ref) & \\
\hline 2nd quartile & $1.516(0.859-2.677)$ & 0.151 & $1.480(0.842-2.610)$ & 0.170 \\
\hline 3 rd quartile & $2.745(1.678-4.49 \mid)$ & $<0.001$ & $2.740(1.675-4.480)$ & $<0.001$ \\
\hline 4th quartile & $4.833(2.994-7.799)$ & $<0.001$ & $4.550(2.815-7.350)$ & $<0.001$ \\
\hline \multicolumn{5}{|l|}{ Model 2} \\
\hline \multicolumn{5}{|l|}{ Quartile of LGI score } \\
\hline Ist quartile & $\mathrm{I} .00$ (ref) & & $1.00($ ref) & \\
\hline 2nd quartile & $1.390(0.787-2.455)$ & 0.257 & I.36I (0.752-2.462) & 0.310 \\
\hline 3rd quartile & $2.376(1.446-3.903)$ & 0.001 & $2.286(1.325-3.945)$ & 0.003 \\
\hline 4th quartile & $4.080(2.420-6.879)$ & $<0.001$ & $3.555(1.802-7.012)$ & $<0.001$ \\
\hline
\end{tabular}

Notes: Model I was adjusted for age and sex; Model 2 was adjusted for age, sex, stroke subtype, education years, smoking status, CRP, WBC count, PLT count, and NLR. Abbreviations: HR, Hazard ratio; Cl, Confidence interval; CRP, C-reactive protein; WBC, White blood cell; PLT, Platelet; NLR, Neutrophil-to-lymphocyte ratio; LGI, low-grade inflammation.

biomarkers. $^{13-15,25}$ Thus we presented an LGI score to evaluate the comprehensive effects on recurrent stroke. ${ }^{26}$

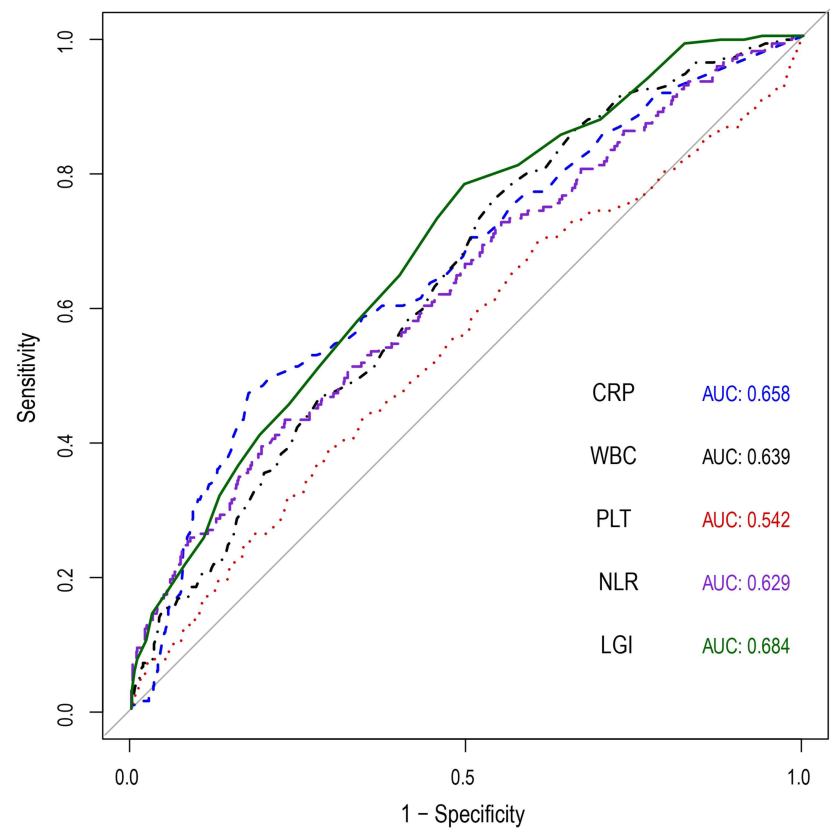

Figure 3 The receiver operating characteristic curves of the low-grade inflammation score and the individual biomarkers.

Abbreviations: CRP, C-reactive protein; WBC, white blood cell; PLT, platelet; NLR, neutrophil-to-lymphocyte ratio; LGI, low-grade inflammation score.
The composite score used by Bonaccio et $\mathrm{al}^{11}$ is a feasible scale to assess the relationship between LGI status and total mortality. In the present study, the fourth quartile of LGI score was significantly associated with the increasing risk of stroke recurrence both in the Cox proportional hazards models and the multivariate competing-risk analyses. Of notice, when we additionally adjusted for age, sex, and factors with a $P$-value $<0.1$ in the univariate analysis, the effect of LGI on recurrent stroke remained robust, which meant that the LGI status was the independent predictor of stroke recurrence. Furthermore, we also evaluated the specific contribution of each biomarker using the ROC curve: CRP, WBC count, and NLR made a significant contribution to the correlation between LGI score and stroke recurrence, nevertheless, the contribution of PLT also should not be neglected. Moreover, blood pressure (BP) at admission, ${ }^{27}$ baseline stroke severity, ${ }^{28}$ stroke etiology, ${ }^{29}$ and education levels ${ }^{11}$ were all related to increased LGI status, which was in line with our research. In the sensitivity analysis, we dichotomized the abovementioned LGI-related factors and test the interaction effect, and found that the association of LGI status with stroke recurrence was higher in the subjects with a lower education level. The possible explanations accounting for 
Table 4 Sensitivity Analysis for the Associations Between Low-Grade Inflammation Score and Stroke Recurrence

\begin{tabular}{|c|c|c|c|c|c|c|}
\hline \multirow[t]{2}{*}{ Subgroups } & \multirow[t]{2}{*}{$\mathbf{N}$ of Events/ $\mathbf{N}$ of Subjects } & \multicolumn{4}{|c|}{ Quartile of LGI Score (HR, 95\% Cl) } & \multirow[t]{2}{*}{ P for Interaction } \\
\hline & & Ist & 2nd & 3 rd & 4th & \\
\hline Sex & & & & & & 0.060 \\
\hline Male & $869 / 1214$ & 1.0 (Ref) & $1.465(0.780-2.750)$ & $2.130(1.211-3.748)$ & $3.137(1.709-5.756)$ & \\
\hline Female & $342 / 1214$ & 1.0 (Ref) & $0.610(0.138-2.710)$ & $2.544(0.895-7.232)$ & $6.292(2.208-17.931)$ & \\
\hline Age & & & & & & 0.339 \\
\hline$<65$ years & $766 / 1214$ & 1.0 (Ref) & $1.941(0.813-4.637)$ & $2.845(1.291-6.265)$ & $2.545(1.088-5.953)$ & \\
\hline$\geq 65$ years & $447 / 1214$ & 1.0 (Ref) & $0.990(0.45 \mathrm{I}-2.174)$ & $2.134(1.082-4.208)$ & $5.654(2.598-12.307)$ & \\
\hline Stroke subtype & & & & & & 0.608 \\
\hline LAA & $469 / 1214$ & 1.0 (Ref) & $1.099(0.445-2.719)$ & $1.774(0.814-3.866)$ & $3.235(1.448-7.227)$ & \\
\hline $\mathrm{CE}$ & $1 / 2 / 1214$ & 1.0 (Ref) & $9.755(0.864-110.134)$ & $7.307(0.682-78.339)$ & $21.707(2.574-183.084)$ & \\
\hline SAA & $245 / 1214$ & 1.0 (Ref) & $2.086(0.464-9.384)$ & $4.743(1.253-17.948)$ & 11.191 (3.003-41.699) & \\
\hline Others & $384 / 1214$ & 1.0 (Ref) & $0.878(0.331-2.327)$ & $1.528(0.656-3.555)$ & $1.550(0.504-4.770)$ & \\
\hline Education & & & & & & $<0.001$ \\
\hline $0-6$ & $3 / 4 / 1214$ & 1.0 (Ref) & $2.047(0.489-8.569)$ & $5.422(1.589-18.493)$ & 16.917 (4.907-58.328) & \\
\hline $6-9$ & $618 / 1214$ & 1.0 (Ref) & I. $107(0.497-2.468)$ & $1.552(0.757-3.182)$ & $1.323(0.534-3.274)$ & \\
\hline $9-12$ & $143 / 12 \mid 4$ & 1.0 (Ref) & $1.432(0.303-6.763)$ & $1.856(0.456-7.556)$ & $18.55 \mid(3.320-103.643)$ & \\
\hline$>12$ & $138 / 1214$ & 1.0 (Ref) & $1.538(0.284-8.339)$ & $1.943(0.240-15.715)$ & $1.905(0.055-65.855)$ & \\
\hline Smoker status & & & & & & 0.752 \\
\hline Nonsmokers & $515 / 1214$ & 1.0 (Ref) & $1.032(0.289-3.682)$ & $3.801(1.443-10.008)$ & 9.899 (3.37I-29.069) & \\
\hline Former & $115 / 1214$ & 1.0 (Ref) & $2.002(0.449-8.926)$ & $2.804(0.573-13.723)$ & $11.604(1.183-113.873)$ & \\
\hline Quitters & $325 / 1214$ & 1.0 (Ref) & $0.675(0.170-2.691)$ & $0.989(0.265-3.691)$ & $1.082(0.185-6.328)$ & \\
\hline Persistent & $254 / 1214$ & 1.0 (Ref) & $1.515(0.562-4.088)$ & $1.742(0.645-4.705)$ & $1.923(0.581-6.357)$ & \\
\hline Baseline NIHSS score & & & & & & 0.630 \\
\hline$<5$ & $703 / 1214$ & 1.0 (Ref) & $1.513(0.740-3.093)$ & $1.822(0.909-3.652)$ & $2.243(0.861-5.843)$ & \\
\hline$\geq 5$ & $510 / 1214$ & 1.0 (Ref) & $0.940(0.325-2.720)$ & $2.371(1.010-5.563)$ & $5.110(2.262-11.547)$ & \\
\hline Baseline SBP & & & & & & 0.326 \\
\hline$<140 \mathrm{mmHg}$ & $541 / 1214$ & 1.0 (Ref) & $1.562(0.662-3.689)$ & $2.995(1.451-6.184)$ & $3.502(1.639-7.482)$ & \\
\hline$\geq 140 \mathrm{mmHg}$ & $671 / 1214$ & 1.0 (Ref) & $1.157(0.536-2.498)$ & $1.843(0.935-3.633)$ & $3.947(1.961-7.946)$ & \\
\hline Baseline DBP & & & & & & 0.619 \\
\hline$<90 \mathrm{mmHg}$ & $873 / 1214$ & 1.0 (Ref) & $1.334(0.7 \mathrm{II}-2.504)$ & $2.516(1.470-4.308)$ & $3.664(2.127-6.312)$ & \\
\hline$\geq 90 \mathrm{mmHg}$ & $339 / 1214$ & 1.0 (Ref) & $2.415(0.591-9.875)$ & $3.334(0.921-12.076)$ & $8.44 \mid(2.3 \mid 3-30.806)$ & \\
\hline
\end{tabular}

Notes: $\mathrm{HR}$ and $95 \% \mathrm{Cl}$ were calculated after adjustment for the same variables as model 2 in Table 3, except for the stratified variable.

Abbreviations: LGI, low-grade inflammation; HR, hazard ratio; Cl, confidence interval; LAA, large-artery atherosclerosis; CE, cardioembolism; SAA, small-vessel occlusion; NIHSS, National Institute of Health Stroke Scale; SBP, systolic blood pressure; DBP, diastolic blood pressure.

this phenomenon are as follows: patients with higher educational levels are more able to control their lifestyle and obey prescriptions after stroke, ${ }^{30-32}$ which are helpful to reduce inflammation and prevent the probability of recurrence.

The possible mechanisms of increased LGI condition on the stroke recurrence are not well defined. CRP has several potential anti-inflammation properties and proinflammatory effects, which may contribute to the progress of atherothrombosis and ischemic injury. ${ }^{33,34}$ Activation of circulating WBC might disturb the microvascular flow and activate the PLT that is associated with endothelial dysfunction and the rupture of the vulnerable plaque. ${ }^{26}$ NLR is considered a good comprehensive indicator of acute inflammation as well as a predictor of recurrent stroke. ${ }^{35}$ Thus, chronic LGI status may be the pivotal factor of atherogenesis, which may ultimately lead to atherosclerotic plaque rupture and induce stroke recurrence. The LGI score, effectively controlling the variability of inflammation biomarkers and considering their possible synergistic effect, was a good predictor of recurrent stroke.

To our knowledge, this is the first study to explore the risk of recurrent stroke in association with a clinically silent LGI status measured by a composite score. The major strengths of this study include a large hospital- 
based cohort, comprehensive assessment of LGI status, and a quite long follow-up period, all of which make this group appropriate for investigating the association between LGI and recurrent stroke. Of notice, to avoid overestimating the risk of LGI status in stroke recurrence, we excluded the patients with acute inflammation or any kind of hematological disease. However, this study has several limitations that should be noted when interpreting the results. First, patients with first-ever ischemic stroke registering in the prospective NSRP may not be generalized to other populations. Second, lifestyle modifications, better patient care, and compliance with medical treatment may interfere with our findings even we considered numerous confounders. Third, we only measured the baseline level of LGI markers and the effect of fluctuation of LGI could not be eliminated. Also, because of the unavailability of the data, other inflammation indicators like tumor necrosis factor-alpha, interleukin-6, and interleukin-8 were not included in the LGI score. Further studies are warranted to assess whether or not the chronic reduction in LGI could decrease the risk of recurrent stroke.

\section{Conclusion}

The present study showed that increased LGI score concerning all possible synergic effects of LGI biomarkers could independently predict stroke recurrence.

\section{Data Sharing and Data Accessibility}

The data in this study are available from the corresponding author (Xinfeng Liu) on a reasonable request.

\section{Ethics Approval and Informed Consent}

Investigation on the NSRP was approved by the Ethics Review Board of Jinling Hospital (approval number 2010NLY-018).

\section{Author Contributions}

All authors made a significant contribution to the work reported, whether that is in the conception, study design, execution, acquisition of data, analysis, and interpretation, or in all these areas; took part in drafting, revising, or critically reviewing the article; gave final approval of the version to be published; have agreed on the journal to which the article has been submitted; and agree to be accountable for all aspects of the work.

\section{Funding}

This study was supported by the National Natural Science Foundation of China (NO. U20A20357), the National Key R\&D Program of China (2017YFC1307901), and the Fundamental Research Funds for the Central Universities.

\section{Disclosure}

All authors report no conflicts of interest in this work.

\section{References}

1. Wang YJ, Li ZX, Gu HQ, et al. China Stroke Statistics 2019: a report from the National Center for Healthcare Quality Management in Neurological Diseases, China National Clinical Research Center for Neurological Diseases, the Chinese Stroke Association, National Center for Chronic and Non-communicable Disease Control and Prevention, Chinese Center for Disease Control and Prevention and Institute for Global Neuroscience and Stroke Collaborations. Stroke Vasc Neurol. 2020;5:211-239.

2. Krishnamurthi RV, Feigin VL, Forouzanfar MH, et al. Global and regional burden of first-ever ischaemic and haemorrhagic stroke during 1990-2010: findings from the Global Burden of Disease Study 2010. Lancet Glob Health. 2013;1:e259-281. doi:10.1016/S2214109X(13)70089-5

3. Mohan KM, Crichton SL, Grieve AP, Rudd AG, Wolfe CD, Heuschmann PU. Frequency and predictors for the risk of stroke recurrence up to 10 years after stroke: the South London Stroke Register. J Neurol Neurosurg Psychiatry. 2009;80:1012-1018. doi:10.1136/jnnp.2008.170456

4. Flach C, Muruet W, Wolfe CDA, Bhalla A, Douiri A. Risk and secondary prevention of stroke recurrence: a population-base cohort study. Stroke. 2020;51:2435-2444. doi:10.1161/STROKEAHA.120.028992

5. Liu X, Xu G, Wu W, Zhang R, Yin Q, Zhu W. Subtypes and one-year survival of first-ever stroke in Chinese patients: the Nanjing Stroke Registry. Cerebrovasc Dis. 2006;22:130-136. doi:10.1159/ 000093241

6. van Wijk I, Kappelle LJ, van Gijn J, et al. Long-term survival and vascular event risk after transient ischaemic attack or minor ischaemic stroke: a cohort study. Lancet. 2005;365(9477):2098-2104. doi:10.1016/S0140-6736(05)66734-7

7. Engström G, Hedblad B, Stavenow L, et al. Incidence of obesity-associated cardiovascular disease is related to inflammation-sensitive plasma proteins: a population-based cohort study. Arterioscler Thromb Vasc Biol. 2004;24:1498-1502. doi:10.1161/01.ATV.0000134293.31512.be

8. Coussens LM, Werb Z. Inflammation and cancer. Nature. 2002;420:860-867. doi:10.1038/nature01322

9. Samuels MA. Inflammation and neurological disease. Curr Opin Neurol. 2004;17:307-309. doi:10.1097/00019052-200406000-00012

10. Barbaresko J, Koch M, Schulze MB, Nöthlings U. Dietary pattern analysis and biomarkers of low-grade inflammation: a systematic literature review. Nutr Rev. 2013;71:511-527. doi:10.1111/ nure. 12035

11. Bonaccio M, Di Castelnuovo A, Pounis G, et al. A score of low-grade inflammation and risk of mortality: prospective findings from the Moli-sani study. Haematologica. 2016;101:1434-1441. doi:10.3324/ haematol.2016.144055

12. Danesh J, Whincup P, Walker M, et al. Low grade inflammation and coronary heart disease: prospective study and updated meta-analyses. BMJ. 2000;321:199-204. doi:10.1136/bmj.321.7255.199

13. Grau AJ, Boddy AW, Dukovic DA, et al. Leukocyte count as an independent predictor of recurrent ischemic events. Stroke. 2004;35:1147-1152. doi:10.1161/01.STR.0000124122.71702.64 
14. Kuwashiro T, Sugimori H, Ago T, Kuroda J, Kamouchi M, Kitazono T. Predictive role of $\mathrm{C}$ reactive protein in stroke recurrence after cardioembolic stroke: the Fukuoka Stroke Registry. BMJ Open. 2013;3:e003678. doi:10.1136/bmjopen-2013-003678

15. Castillo J, Alvarez-Sabín J, Martínez-Vila E, Montaner J, Sobrino T, Vivancos J. Inflammation markers and prediction of post-stroke vascular disease recurrence: the MITICO study. $J$ Neurol. 2009;256:217-224. doi:10.1007/s00415-009-0058-4

16. Kim S, Eliot M, Koestler DC, Wu WC, Kelsey KT. Association of neutrophil-to-lymphocyte ratio with mortality and cardiovascular disease in the Jackson heart study and modification by the Duffy antigen variant. JAMA Cardiol. 2018;3:455-462. doi:10.1001/ jamacardio.2018.1042

17. Xu G, Liu X, Wu W, Zhang R, Yin Q. Recurrence after ischemic stroke in Chinese patients: impact of uncontrolled modifiable risk factors. Cerebrovasc Dis. 2007;23:117-120. doi:10.1159/000097047

18. Goldstein LB, Samsa GP. Reliability of the National Institutes of Health Stroke Scale. Extension to non-neurologists in the context of a clinical trial. Stroke. 1997;28:307-310.

19. Adams HP Jr, Bendixen BH, Kappelle LJ, et al. Classification of subtype of acute ischemic stroke. Definitions for use in a multicenter clinical trial. TOAST. Trial of Org 10172 in Acute Stroke Treatment. Stroke. 1993;24:35-41. doi:10.1161/01.STR.24.1.35

20. Ramanujam R, Hedstrom AK, Manouchehrinia A, et al. Effect of smoking cessation on multiple sclerosis prognosis. JAMA Neurol. 2015;72:1117-1123. doi:10.1001/jamaneurol.2015.1788

21. Chen J, Li S, Zheng K, et al. Impact of smoking status on stroke recurrence. J Am Heart Assoc. 2019;8:e011696. doi:10.1161/ JAHA. 118.011696

22. Stroke. Recommendations on stroke prevention, diagnosis, and therapy. Report of the WHO Task Force on Stroke and other Cerebrovascular Disorders. Stroke. 1989;20:1407-1431. doi:10.1161/01.STR.20.10.1407

23. Geskus RB. Cause-specific cumulative incidence estimation and the fine and gray model under both left truncation and right censoring. Biometrics. 2011;67:39-49. doi:10.1111/j.1541-0420.2010.01420.x

24. Oza R, Rundell K, Garcellano M. Recurrent ischemic stroke: strategies for prevention. Am Fam Physician. 2017;96:436-440.
25. Welsh P, Lowe GDO, Chalmers J, et al. Associations of proinflammatory cytokines with the risk of recurrent stroke. Stroke. 2008;39:2226-2230. doi:10.1161/STROKEAHA.107.504498

26. Gawaz M, Langer H, May AE. Platelets in inflammation and atherogenesis. J Clin Invest. 2005;115:3378-3384. doi:10.1172/ JCI27196

27. Di Napoli M, Papa F. Systemic inflammation, blood pressure, and stroke outcome. J Clin Hypertens. 2006;8:187-194. doi:10.1111/ j.1524-6175.2005.04590.x

28. Zhou X, Yu F, Feng X, et al. Immunity and inflammation predictors for short-term outcome of stroke in young adults. Int $J$ Neurosci. 2018;128:634-639. doi:10.1080/00207454.2017.1408614

29. Zhang XG, Xue J, Yang WH, et al. Inflammatory markers as independent predictors for stroke outcomes. Brain Behav. 2021;11: e01922. doi: 10.1002/brb3.1922

30. Pennlert J, Asplund K, Glader EL, Norrving B, Eriksson M. Socioeconomic status and the risk of stroke recurrence: persisting gaps observed in a nationwide Swedish study 2001 to 2012. Stroke. 2017;48:1518-1523. doi:10.1161/STROKEAHA.116.015643

31. Sjölander M, Eriksson M, Glader EL. Social stratification in the dissemination of statins after stroke in Sweden. Eur $J$ Clin Pharmacol. 2013;69:1173-1180. doi:10.1007/s00228-012-1454-8

32. Sjölander M, Eriksson M, Asplund K, Norrving B, Glader EL. Socioeconomic inequalities in the prescription of oral anticoagulants in stroke patients with atrial fibrillation. Stroke. 2015;46:2220-2225. doi:10.1161/STROKEAHA.115.009718

33. Zwaka TP, Hombach V, Torzewski J. C-reactive protein-mediated low density lipoprotein uptake by macrophages: implications for atherosclerosis. Circulation. 2001;103:1194-1197. doi:10.1161/01. CIR.103.9.1194

34. Lagrand WK, Visser CA, Hermens WT, et al. C-reactive protein as a cardiovascular risk factor: more than an epiphenomenon? Circulation. 1999;100:96-102.

35. Xue J, Huang W, Chen X, et al. Neutrophil-to-lymphocyte ratio is a prognostic marker in acute ischemic stroke. J Stroke Cerebrovasc Dis. 2017;26:650-657. doi:10.1016/j.jstrokecerebrovasdis.2016. 11.010
Journal of Inflammation Research

\section{Publish your work in this journal}

The Journal of Inflammation Research is an international, peerreviewed open-access journal that welcomes laboratory and clinical findings on the molecular basis, cell biology and pharmacology of inflammation including original research, reviews, symposium reports, hypothesis formation and commentaries on: acute/chronic inflammation; mediators of inflammation; cellular processes; molecular mechanisms; pharmacology and novel anti-inflammatory drugs; clinical conditions involving inflammation. The manuscript management system is completely online and includes a very quick and fair peerreview system. Visit http://www.dovepress.com/testimonials.php to read real quotes from published authors. 